DOI 10.37882/2223-2982.2021.12-2.28

\title{
КОГЕЗИЯ И КОГЕРЕНТНОСТЬ В АНГЛИЙСКОЙ РЕЧИ В ПУБЛИЦИСТИЧЕСКИХ ТЕКСТАХ
}

\section{COHERENCE AND COHERENCE IN ENGLISH SPEECH IN JOURNALISTIC TEXTS \\ O. Murai}

Summary: The article examines the actual problem of coherence and coherence in English speech in journalistic texts.

The language of the newspaper, of course, has a certain specificity that distinguishes it from the language of fiction or scientific literature, from colloquial discourse. This is a consequence of a long-term choice of the most appropriate language means of expression for the social task that the newspaper performs as the main means of communication. The desire to deliver the latest news as quickly as possible is reflected both in the nature of communicative tasks and in their verbal embodiment. The newspaper is designed for a wide range of readers and should attract attention.

The language of news reports, historically developed in the English literary system, has a number of common characteristics that vary from era to era, as well as many characteristics inherent in certain genres and newspaper publications. But, despite the heterogeneity of the system of language tools used in different types of newspapers, the style of a newspaper always differs from other styles of speech in a number of significant common characteristics.

TheXXI century poses new challenges to the information space of mankind. The infinite diversity of the modern world is transmitted through the mass media in the experience and interpretations of numerous participants in the international information process - journalists, correspondents, commentators, cameramen. Social changes are reflected in language as in a mirror. The journalistic style is more aware of these changes more than any other language style. Therefore, translation activity is becoming more and more important, and translation problems arise with it. [1].

Keywords: cohesion and coherence, journalistic text, reference, substitution, ellipse.

\author{
Мурай Ольга Викторовна \\ К.филол.н., РУТ МИИТ \\ murray007@mail.ru
}

Аннотация: В статье исследуется актуальная проблема - когезия и когерентность в английской речи в публицистических текстах.

Язык газеты, конечно, имеет определённую специфику, которая отличает его от языка художественной или научной литературы, от разговорного дискурса. Это следствие долгого выбора языковых средств выражения, подходящих для социальной задачи, которую газета выполняет как основное средство массовой информации. Желание быстро донести самые свежие новости отражается на характере коммуникативных задач и на их речевом воплощении. Газета рассчитана на широкий круг читателей и должна привлекать внимание.

Язык газетных сообщений, исторически сложившийся в системе английского литературного языка, имеет ряд общих черт, меняющихся от эпохи к эпохе, многие особенности, присущие определённым жанрам и газетным публикациям. Но при всей неоднородности системы языковых средств, которые используются в разных жанрах газет, газетный стиль всегда отличается от других стилей речи существенными общими характеристиками.

XXI век ставит перед информационным пространством человечества новые вызовы. Огромное разнообразие современного мира передаётся СМИ в ощущениях и интерпретациях участников международного информационного процесса - журналистов, корреспондентов, комментаторов и операторов. Социальные изменения отражаются в языке как в зеркале. Журналистский стиль воспринимает эти изменения больше, чем другие языковые стили. Поэтому переводческая деятельность становится более важной, и с ней возникают проблемы с переводом. [1].

Ключевые слова: когезия и когерентность, публицистический текст, референция, замещение, эллипс.
$\Pi$ онятие журналистского стиля очень объёмно, мы исследуем в своей работе один слой журналистики: стиль газеты. Тема становится актуальнее с каждым годом, потому что современный человек узнаёт о мировых событиях и развитии международных отношений, в основном, через прессу. Для современного читателя становятся интересными публикации в зарубежной прессе. В наши дни очень важно точно донести информацию до зарубежной прессы. Это адекватный перевод текстов прессы, который поможет детально разобраться в изменениях общественной жизни в англоязычном мире.

Во-первых, цель написания газет и журналов - доне- сти новую информацию и повлиять на читателя. Поэтому обращайте внимание на источник информации. Текст газеты полон специфических терминов из политической и государственной жизни, представленных в виде сокращений. Например: AFLCIO = American Federation of Labor-Congress of Industrial Organizations, DD = Defense Department, GOP = Grand Old (Republican) Party, NAACP $=$ National Association for Advancement of Colored People, RAF - Royal Air Force (Королевские военно-воздушные силы); PM - Prime Minister (премьер-министр); ASBO antisocial behaviour order (решение суда Великобритании об антисоциальном поведении); MRSA - methicillinresistant Staphylococcus aureus (стафилококковая 
бактерия, устойчивая к метициллину); AWOL - absent without leave (самовольное отсутствие, дезертирство военная формулировка); АTM - automated teller machine (автоматический кассовый аппарат); MCB - Muslim Council of Britain (Совет мусульман Великобритании); VC - Victoria Cross (Викторианский крест - медаль); IVF in vitro fertilization (искусственное («в пробирке») оплодотворение). Часто используются сокращения фамилий или привычных прозвищ известных политических или общественных деятелей: Rocky = Rockefeller, JFK = John F, Kennedy, RLS = Robert Louis Stevenson Ike = Eisenhower, etc [3]. Использование только фамилии героя газетной публикации в заголовке является наиболее распространенным способом в The T i m e s: большинство заголовков, содержащих имена собственные, включают упоминание героя по фамилии: Callaqhan agreed payout for terrorist suspect; Bush's law chief facing test on human right; Putin aide pays for Yukos attack.

За границей читатель привык к такой журналистской свободе. Если эта особенность будет сохранена во время перевода, воздействие на читателя будет другим, чем в оригинале, что несовместимо с концепцией адекватности перевода. Поэтому сокращённые названия следует давать полностью, а псевдонимы с комментариями или без них.

В публицистическом тексте репрезентанты квантификаторов (повторяющихся слов -связок) часто выражены числительными или наречиями. Порядковые числительные выполняют в предложении те же функции, что и количественные числительные. Например: The first chapter is the most interesting. (функция определения). I asked two students. The first answered much better than the second. (функция подлежащего)

Таким образом, журналистский стиль - один из функциональных стилей, обслуживающий широкий спектр социальных отношений: политических, экономических, культурных, спортивных, но в то же время воспринимается через призму определённых политических и идеологических взглядов.

М. Халлидей и Р. Хасан различают пять форм целостности текста: референция, замещение, эллипс, союз (связь) и лексическая связность, авторы указывают на отсутствие постоянных границ между этими категориями. Категории связности - явления структурных, грамматических и лексических отношений. Указанные пять средств когерентности основаны на 2-х типах отношений - идентичности упомянутых предметов, явлений или их сочетании.

Ссылка - замена имени, свойства или действия в связном сегменте текста определёнными детерминантами, а именно: местоимением (личным, указательным, притя- жательным); слова с количественным или качественным значением - первое: было двое мужчин - the first: There were two men. The first...), as many. И замещающий, и замещаемый имеют общий референт реальности - объект, свойство или действие, указанные в тексте, и взаимосвязаны однородные элементы (He - John). Другими примерами катафоры того же типа являются: After he had received his orders, the soldier left the barracks. If you want them, there are cookies in the kitchen. Катафора в предложениях часто используется для риторического эффекта. Это может создать нарастание событий и дать описание героя. Например: He's the biggest slob I know. He's really stupid. He's so cruel. He's my boyfriend Nick.

Подстановка отличается от ссылки тем, что заменяет отдельные имена группами слов или фраз. Итак, в катафорическом примере: I'll tell you this. Don't be impatient this обозначает всю следующую заменяющую фразу. В отличие от ссылки элемент, заменяющий другой, принадлежит другому классу.

Такие слова, как частицы, союзы, указательные местоимения часто служат заменителями - the same, likewise, that (I'll do the same/likewise, that), be, do (Do, please!), so, not (I think so/not).

Замена групп глаголов производится вспомогательными и модальными глаголами и глаголами с широким вариативным значением, что может создавать игру слов в тексте (например, make сочетается с различными существительными - make a joke - шутить; make a mistake совершить ошибку; make a profit- получать прибыль и т.д.). В таких случаях замена увязывается со следующей категорией согласованности эллипса. Эллипсис как прием означает опускание слов в беседе, если значение высказывания при этом сохраняется. Чаще всего подобное опущение происходит со словами в начале предложения или недалеко от него. Вспомогательный глагол How are (опускаемый элемент) уоu doing? - Как ты поживаешь? Эллиптическое предложение - How you doing? - Как ты?

Эллипс, как и подстановка, в основном характерен для диалога. Он служит средством коммуникации, так как может опускать несколько предыдущих предложений или целые предложения, содержание которых отражено в предыдущем элементе и исходит из предыдущего контекста. Вот несколько примеров эллипсов из книги М. Халлидея и Р. Хасана: Fortunately for him, or for you? Oh, for me (вместо fortunately); And I thought it better not to (to заменяет предыдущее действие). В последнем случае линия между эллипсами и заменой стирается.

Союзное слово (коннектор) очень распространено и обширно по количеству лексических единиц и по разнообразию выражаемых ими логических отношений. В когезивные материалы входят не только слова (чаще 
всего ассоциации), но и словосочетания (on the contrary, in such an event и т.п.), а также целые предложения (I mean и т.п.). Связующим элементом между предложениями служит и отрицание, более или менее нейтральное в стилистическом отношении. Эти коннекторы могут не только являться связующими единицами между предложениями, но и начинать собою абзац или сверхфразовое единство с новой темы. Например:

I heard he sang a good song, I heard he had a style

And so I came to see him, to listen for a while

And there he was, this young boy, a stranger to my eyes I felt all flushed with fever, embarrassed by the crowd....

Пятая категория связности - лексическая связность. Согласованность текста достигается за счёт повторения лексических единиц и их чередования в разных формах на основе слов и словосочетаний предметной области, а также за счет развития синонимичных и синонимичных единиц. И. Хлебникова иллюстрирует этот феномен на примерах из книги М. Халлидея, Р. Хасана: Примеры использования сплоченности:

being alone - solitude - the bad thing

Замена предмета, действия или состояния - широко распространённое явление. Для этого используются слова с широкой семантикой - thing, matter, business, object, person, people, place, question и т.п. Эта замена соединяется с категорией субституции.

-handedly, meaninglessly reports - it is plain silly» (Waterhouse, 1989).

Меры согласованности в тексте можно классифицировать по разным критериям. Тексты можно разделить на связанные грамматически, логически, образно, ассоциативно, композиционно-структурно, в рамках ритмики и стилистики.

Традиционные грамматические особенности включают союзы и родственные выражения этого типа, т.е. как и все средства (местоимения, союзы и т.д.); причастия (например, в упомянутых выше дипломатических документах). Эти меры называются традиционными грамматическими средствами согласованности, они были описаны как средства связи между определёнными предложениями. Но они также служат средством связи между более крупными сегментами - абзацами, и в этом отношении им присваивается статус связности. [2].

Стиль бульварной прессы - сложный конгломерат словесных игр, пословиц, поговорок, аллюзий, клише и политической лексики. Например:

1. обилие разговорной лексики: to bar, to ax, to ban;

2. сленга: booze «алкоголь»; to snog «целовать»

3. фразеологизмов: to give smb. the boot «уволить»;

4. клише plea of mercy, terrible tension;

5. терминов: leukaemia, mortgage.
Таким образом, газетные текстовые категории воплощены в статьях «human interest stories» такими характеристиками, как информативность и модальность на лексико-стилистическом и морфологическом уровнях, целостность, связность и артикуляция на синтаксическом уровне.

Приведем выборочный анализ синонимии и словосочетаний в некоторых газетных статьях. В следующей части представлены результаты анализа когерентности в отдельных выдержках из новостных жанровых текстов, которые освещают возникновение взаимосвязанных категорий с точки зрения словосочетания и синонимии в публицистическом жанре. Символ $(\rightarrow)$ показывает, что существует перспективная или ретроспективная связь между словосочетанием/синонимией, тем самым устанавливая согласованность в дискурсе.

\section{Новостная статья. Образеи 1.}

Ms. Merkel was informed of the case on Thursday, her spokesman said, just before she spoke to President Obama by telephone. But the White House described that conversation as one that was primarily about Ukraine and the continuing negotiations with Iran over its nuclear program. Neither German nor American officials would say on the record whether the subject of the arrest came up during the call. But another senior United States official, speaking on the condition of anonymity because the president's conversations were intended to be private, said the issue did not come up on the call, which was previously scheduled to discuss other matters, and that Mr. Obama was not aware of the case at the time of the call. В этом абзаце некоторые из взаимосвязанных терминов проявляются в различных лексических цепочках. Встречаемость связующих словосочетаний более заметна, чем когерентность в синонимах. Можно выделить следующие связующие цепочки:

Словосочетания:

1. Was informed - spoke - by telephone $\rightarrow$

2. Telephone - conversation $\rightarrow$

3. Call - telephone $\rightarrow$

4. White House - American officials

5. Aware-be informed

6. Discuss - other matters $\rightarrow$

7. Issue - come up

Синонимы:

1. Subject - issue - matters - case

2. Anonymity - private

\section{Новостная статья. Образец 2.}

The report has been issued just as Congress is considering changes in the laws governing N.S.A activities. But 
the legislation which has passed the House and is under consideration by the Senate, deals largely with the call-records program, which the board and President Obama said in January must be changed. That program involved the agency's retention of billions of records for all phone calls made from or to the United States; under the legislation, telecommunications companies would retain those records, and the N.S.A. would have access under court orders. Словосочетания и синонимичные слова составляют связующие связи в этом абзаце. Словосочетания доминируют при согласовании текста.

Словосочетания:

1. The report - issued

2. Consider-changes

3. Changes - in the laws $\rightarrow$

4. Governing - NSA activities

5. Legislation - passed -House - senate $\rightarrow$

6. Retention - of records

7. Record of - phone call - telecommunications

\section{Court-orders}

Синонимы:

1. Law-legislation

Анализ новостных статей показывает, что большинство связных цепочек в этом жанре включают словосочетательный тип лексической связности, в то время как синонимичные термины встречаются в небольшом количестве когезионных цепочек. Эллипсы также могут присутствовать в лексических цепочках синонимов и словосочетаний. С другой стороны, новостной жанр и средства массовой информации преследуют цель убедить читателя, и представляют определенное идеологическое и политическое мировоззрение. Изучение когезионных приемов в этом жанре и организации некоторых типов когезии показывает тот факт, что словосочетание более ярко выражает когезию текста, синонимия при этом занимает второе место по значимости.

\section{ЛИТЕРАТУРА}

1. Васильева А.Н. Газетно-публицистический стиль речи. - М.: Русский язык, 1982. - 200 с.

2. Гальперин И.Р. Текст как объект лингвистического исследования. - М.: Наука, 1981 - 140 с.

3. Зайцева Н.В. Роль антонимов в обеспечении структурно-семантического единства текста [Текст] / Н.В. Зайцева //Актуальные проблемы современной лингвистики: Всероссийская научная конференция. - Ростов н/Д: РГУ Лингвистический институт,2005 (0,2 п.л.).

4. Наер В.Л. К описанию функционально-стилевой системы современного английского языка // Лингвостилистические особенности научного текста: сб. научн. тр. / - М., 1981 - с. 3 - 13.

5. Никулина Н.Ю. Специфические особенности перевода англоязычных газетно-публицистических текстов [Текст] / Н.Ю. Никулина, Т.А. Зиновьева // Молодой ученый. — 2013. — №1.

(с) Мурай Ольга Викторовна (murray007@mail.ru).

Журнал «Современная наука: актуальные проблемы теории и практики» 